\title{
Minireviews
}

\section{Genetic Association of Single Nucleotide Polymorphisms with Acetaminophen-Induced Hepatotoxicity}

\author{
DDaniel P. Heruth, Katherine Shortt, Nini Zhang, Ding-You Li, Li Q. Zhang, \\ and Shui Qing Ye
}

Division of Experimental and Translational Genetics, Department of Pediatrics, Children's Mercy (D.P.H., K.S., N.Z., L.Q.Z., S.Q.Y.), Division of Gastroenterology, Department of Pediatrics, Children's Mercy (N.Z., D.-Y.L.), and Department of Biomedical and Health Informatics (K.S., S.Q.Y.), University of Missouri Kansas City School of Medicine, Kansas City, Missouri; Division of Cell Biology and Biophysics, University of Missouri Kansas City School of Biological Sciences, Kansas City, Missouri (K.S.); and Department of Pediatrics, Tangdu Hospital, The Fourth Military Medical University, Xian, China (N.Z.)

Received February 18, 2018; accepted August 1, 2018

\section{ABSTRACT}

Acetaminophen is commonly used to reduce pain and fever. Unfortunately, overdose of acetaminophen is a leading cause of acute liver injury and failure in many developed countries. The majority of acetaminophen is safely metabolized in the liver and excreted in the urine; however, a small percentage is converted to the highly reactive $N$-acetyl- $p$-benzoquinone imine (NAPQI). At therapeutic doses, NAPQI is inactivated by glutathione $S$-transferases, but at toxic levels, excess NAPQI forms reactive protein adducts that lead to hepatotoxicity. Individual variability in the response to both therapeutic and toxic levels of acetaminophen suggests a genetic component is involved in acetaminophen metabolism. In this review, we evaluate the genetic association studies that have identified 147 single nucleotide polymorphisms linked to acetaminophen-induced hepatotoxicity. The identification of novel genetic markers for acetaminophen-induced hepatotoxicity provides a rich resource for further evaluation and may lead to improved prognosis, prevention, and treatment.

\section{Introduction}

Acetaminophen (paracetamol) is a commonly used analgesic and antipyretic; however, high nontherapeutic doses can cause severe liver injury. Although acetaminophen overdose is a major cause of hepatotoxicity in many developed countries, drug-induced liver injury (DILI) is not unique to acetaminophen, as more than $50 \%$ of acute liver failure (ALF) cases have been attributed to the hepatic biotransformation of a wide array of small-molecule drugs (Lee, 2003). Acetaminophen should be considered a dose-dependent hepatotoxin since most cases of toxicity are secondary to excessive dosing of acetaminophen (Nourjah et al., 2006). Thus, the DILI induced by acetaminophen is classified as intrinsic (dose dependent) instead of idiosyncratic (dose independent) (Lee, 2013; Mosedale and Watkins, 2017).

Approximately $90 \%$ of a therapeutic dose of acetaminophen is metabolized completely by multiple enzymes in the liver and,

https://doi.org/10.1124/jpet.118.248583. along with $5 \%$ of nonmetabolized acetaminophen, eventually excreted in urine and bile (Raheja et al., 1983; Vermeulen et al., 1992). The majority of acetaminophen is detoxified via formation of either glucuronide $(\sim 50 \%)$ or sulfate $(\sim 40 \%)$ conjugates by uridine 5' -diphospho-glucuronosyltransferases (e.g., UGT1A1, UGT1A6, UGT1A9, UGT2B7, UGT2B15) and sulfotransferases (e.g., SULT1A1, SULT1A3, SULT1A4, SULT1E1, SULT2A1), respectively. However, a small percentage of ingested acetaminophen $(\sim 5 \%)$ is metabolized by oxidation via the microsomal cytochrome $\mathrm{P} 450$ pathway into $N$-acetyl$p$-benzoquinone imine (NAPQI) (Corcoran et al., 1980, 1985). The cytochrome P450 (P450) enzymes, including CYP1A2, CYP2A6, CYP2D6, CYP2E1, and CYP3A4, convert acetaminophen into the highly reactive NAPQI metabolite (Raucy et al., 1989; Thummel et al., 1993; Lee et al., 1996; Chen et al., 1998; Dong et al., 2000). At toxic acetaminophen levels, CYP3A4 presented with the highest relative capacity for acetaminophen bioactivation to NAPQI by oxidation, followed by CYP2E1, CYP2D6, and CYP1A2 (Laine et al., 2009). At therapeutic acetaminophen levels, CYP3A4 again had the

ABBREVIATIONS: ALF, acute liver failure; ALI, acute liver injury; ALT, alanine aminotransferase; DILI, drug-induced liver injury; GPX, glutathione peroxidase; GST, glutathione S-transferase; GWAS, genome-wide association study; MAF, minor allele frequency; NAPQI, $N$-acetyl- $p$-benzoquinone imine; OR, odds ratio; P450, cytochrome P450; rs, rs accession number; SNP, single nucleotide polymorphism; SULT, sulfotransferase; UGT, uridine 5'-diphospho-glucuronosyltransferase. 
highest rate of conversion to NAPQI, whereas the other P450 enzymes possessed a significantly lower capacity for bioactivation (Laine et al., 2009). NAPQI, a strong oxidizer that is toxic to liver tissue, is reduced (inactivated) by conjugation with glutathione by glutathione $S$-transferases (GSTs), a family of enzymes (e.g., GSTT1, GSTP1) responsible for the detoxification of many drugs (Dahlin et al., 1984). The toxicity of NAPQI is associated with its ability to bind to cysteine residues in proteins to form NAPQI-protein adducts (Jollow et al., 1973; Davern et al., 2006). At therapeutic doses, the small amount of NAPQI-protein adducts produced are removed effectively by autophagy (McGill et al., 2013; Ni et al., 2016). However, in the case of acute and chronic overdoses of acetaminophen, the SULT and UGT enzymes become saturated, shifting the metabolism of acetaminophen through the P450 enzymes to produce increased levels of NAPQI. Subsequently, NAPQI depletes hepatic glutathione and accumulates in hepatocytes where excess NAPQI binds to cysteine residues (Leeming et al., 2015) on cellular (Cohen et al., 1997) and mitochondrial proteins (Tirmenstein and Nelson, 1989), leading to acute liver injury (ALI) or the more severe ALF.

The current model of acetaminophen-induced hepatic necrosis links the NAPQI-protein adducts with amplified cascades of reactive oxygen and nitrogen species, resulting in the swift loss of hepatic cells and liver function (Ramachandran and Jaeschke, 2017; Wang et al., 2017). This model has been reviewed thoroughly (Russmann et al., 2009, 2010; Hinson et al., 2010; Fontana, 2014; Krasniak et al., 2014), but in brief, the reactive oxygen species/reactive nitrogen species induce increased mitochondrial permeability, resulting in impaired mitochondrial function (McGill et al., 2012; Jiang et al., 2015) and leading to the initiation of massive necrotic cell death. Subsequently, necrotic hepatocytes release damageassociated molecular patterns resulting in an immune response mediated by various cytokines and innate immune cells (Bourdi et al., 2007; Wang et al., 2015; Fannin et al., 2016).

Although acetaminophen is a dose-dependent hepatotoxin, elevated alanine aminotransferase (ALT) serum levels were measured in some healthy adults following a 7-14-day administration of the maximum daily dose of $4 \mathrm{~g}$ per day (Watkins et al., 2006; Harrill et al., 2009b). Additional case studies, although rare, have reported the development of ALI even at therapeutic doses (Kurtovic and Riordan, 2003; Satirapoj et al., 2007). These findings confirm that some healthy individuals experience mild to severe liver injury in response to therapeutic doses of acetaminophen, suggesting that genetic components are involved in acetaminophen metabolism. Thus, several groups have proposed that NAPQI toxicity can be enhanced by alterations in the metabolism of acetaminophen due to genetic polymorphisms in the corresponding enzymes (Adjei et al., 2008; Zhao and Pickering, 2011; Krasniak et al., 2014). Single nucleotide polymorphisms (SNPs) in metabolic enzymes have been predicted to explain both the ethnic and interindividual differences in acetaminophen degradation and hepatotoxicity (Critchley et al., 1986, 2005). This concept is not unique to acetaminophen-induced hepatotoxicity, as genetic variations in cellular stress, drug metabolism, and immune response genes are associated with DILI susceptibility (Daly and Day, 2012; Chen et al., 2015). Numerous SNPs have been identified that alter the activity of drug-metabolizing enzymes, including SULT, UGT, and P450
(Chambers et al., 2011; Zhao and Pickering, 2011; Krasniak et al., 2014), yet very few SNPs have been experimentally associated directly with acetaminophen-induced hepatotoxicity (Ueshima et al., 1996; Court et al., 2013, 2014). Genomewide association studies (GWAS) provide a powerful tool to scan for SNPs that associate with a disease phenotype, such as hepatotoxicity. GWAS in idiosyncratic DILI have identified pharmacogenetic polymorphisms (Chambers et al., 2011; Urban et al., 2012; Petros et al., 2017) associated with liver injury following treatment with statins (Nicoletti et al., 2017), flucloxacillin (Daly et al., 2009), amoxicillin-clavulanate (Lucena et al., 2011), flupirtine (Nicoletti et al., 2016), and antituberculosis drugs (Petros et al., 2016). Unfortunately, large-scale GWAS for acetaminophen-induced hepatotoxicity have not been performed to date.

To overcome the limitations of GWAS in human cohorts, several groups have performed innovative experiments using mouse models and/or human tissue culture assays to identify and characterize SNPs associated with acetaminopheninduced hepatotoxicity. Therefore, this review explores the candidate gene and genome-wide approaches that have identified 147 SNPs associated with either protection against or susceptibility to acetaminophen-induced hepatotoxicity. The inclusion criteria used in this review were to include all human SNPs that: 1) have been experimentally identified for a significant association with acetaminophen-induced hepatotoxicity using candidate gene and genome-wide approaches, and 2) have been annotated with an rs accession number (rs).

The clinical utilities of pharmacogenetics and pharmacogenomics are becoming increasingly important for optimizing individual patient care. Although the application of genetic information has not yet been applied formally to acetaminophen dosing, the studies presented here provide the foundation for critical translational research in DILI. The identification of SNPs associated with a significant risk for acetaminopheninduced hepatotoxicity will provide potential targets for improved prognosis, prevention, and treatment.

\section{Candidate Gene Approaches to Identify SNPs Associated with Acetaminophen-Induced Hepatotoxicity}

Ueshima et al. (1996) described a CYP2E1 promoter SNP (rs2031920, C $>$ T) that was associated with altered acetaminophen metabolism. rs2031920 is common in East Asian populations with a minor allele frequency (MAF) of 0.20 but is rare in other ethnic groups. Homozygous carriers of the rs2031920 variant $T$ allele presented with a 2 -fold increase in the elimination rate of acetaminophen compared with $\mathrm{CC}$ and CT individuals (Ueshima et al., 1996), which correlated with increased promoter activity due to the homozygous minor genotype (Hayashi et al., 1991) and higher hepatic levels of CYP2E1 (Tsutsumi et al., 1994). We can predict that elevated levels of CYP2E1 would result in increased production of NAPQI and could lead to a greater risk of acetaminopheninduced hepatotoxicity in homozygous TT individuals. However, GWAS in acetaminophen-induced hepatotoxicity cohorts have not yet identified rs2031920 as a susceptibility locus.

Court et al. (2013) identified three 3'untranslated region SNPs (rs8330, C>G; rs10929303, C > T; rs1042640, C>G) in the UGT1A gene that were associated with increased 
glucuronidation activity following acetaminophen exposure. The UGT1A rs8330 MAF (G) was significantly lower in the unintentional acetaminophen hepatotoxicity group (0.16) compared with the other ALF subgroups (0.22), with an odds ratio (OR) of $0.53(0.30-0.94 ; P=0.027)$ (Court et al., 2014) (Table 1). This finding was consistent with a protective effect of the variant rs8330 G allele through enhancement of acetaminophen glucuronidation and detoxification, as demonstrated by a series of in vitro mechanistic studies by Court et al. (2013). rs8330 increased glucuronidation activity due to altered splicing of the primary UGT1A transcript, resulting in the preferential retention of exon $5 \mathrm{~A}$ versus exon $5 \mathrm{~B}$. Translation of UGT1A mRNA containing exon $5 \mathrm{~B}$ produces a truncated UGT1A protein, termed isoform two variant, which lacks enzymatic activity and further represses enzymatic activity through heterodimerization with the wild-type isoform (Court et al., 2013). Similar to rs2031920, the rs8330 MAF varies among ethnic populations.

Court et al. (2014) evaluated the association with acetaminophen-induced hepatotoxicity in a panel of polymorphisms from genes encoding known acetaminophenmetabolizing enzymes, including UGT1A, UGT1A1, UGT1A6, UGT1A9, UGT2B15, SULTA1, CYP2E1, and CYP3A5. They also analyzed a polymorphism in $C D 44$ that was associated with elevated serum ALT levels in healthy volunteers who consumed the maximum recommended dose of acetaminophen for up to 2 weeks (Watkins et al., 2006; Harrill et al., 2009b). Three genes, CYP3A5, UGT1A, and CD44, contained SNPs with relatively weak associations with acetaminophen-induced liver injury in an acute liver failure study group cohort of 260 Caucasian individuals, which consisted of 78 patients with intentional acetaminophen overdose, 79 patients with unintentional acetaminophen overdose, and 103 patients with ALF due to nonacetaminophen-associated causes.

The CYP3A5 splice donor variant ( $r 5776746, \mathrm{G}>\mathrm{A}$ ) is associated with acetaminophen-induced hepatotoxicity (Table 1). The minor A allele (also known as $C Y P 3 A 5^{*} 1$ ) encodes a functional cytochrome $\mathrm{P} 450$ family 3 subfamily A member 5 protein, whereas a nonfunctional protein is produced from CYP3A5 genes containing the major $\mathrm{G}$ allele (rs776746; CYP3A5*3) (Kuehl et al., 2001). The CYP3A5*1 A allele was observed more frequently in intentional acetaminophen overdose cases compared with all other acute liver failure patients (Court et al., 2014). The heterozygous GA genotype was an "at risk" genotype with $\mathrm{OR}=2.3(1.1-4.9 ; P=0.034)$ (Court et al., 2014). The homozygous AA genotype was not observed in this cohort. Subsequently, the CYP3A5 diplotypes have been correlated with phenotypes for the metabolism of drugs, such as tacrolimus: $* 1 / * 1$, extensive metabolizer; ${ }^{*} 1 / * 3$, intermediate metabolizer; $* 3 / * 3$, poor metabolizer (Tanaka et al., 2014; Birdwell et al., 2015). The MAF for the rs776746 A allele $\left({ }^{*} 1\right)$ in this cohort of 260 Caucasians was 0.06, which is the same as the European population. Although the rs776746 MAF varies among ethnic groups, it did not correlate with the incidence of acetaminophen-induced hepatotoxicity across stratified ethnic groups (Critchley et al., 1986; Patel et al., 1992; Russo et al., 2004; Marzilawati et al., 2012).

The CD44 rs1467558 (C>T) TT minor allele genotype was over-represented in the unintentional hepatotoxicity group, with $\mathrm{OR}=4.0(1.0-17.2 ; P=0.045)$ (Court et al., 2014), suggesting that rs1467558 TT is an "at risk" genotype (Table 1). This observation was supported by previous studies that revealed rs1467558 is associated with elevated serum ALT levels (Watkins et al., 2006; Harrill et al., 2009b). In silico mechanistic structural analysis predicted that rs 1467558 can alter many of the complex, alternative CD44 transcripts, including a potentially damaging amino acid change from threonine to isoleucine (Harrill et al., 2009b). Interestingly, CD44 is not an acetaminophenmetabolizing enzyme, but rather a cell surface receptor involved in cell-cell interactions, cell adhesion, and cell migration in inflamed tissue (Kimura et al., 2010).

The rs1902023 (G>T) missense polymorphism in UGT2B15 (termed UGT2B15*2) was associated with lower acetaminophen glucuronide-to-acetaminophen concentration ratios in urine (Navarro et al., 2011) and blood (Mehboob et al., 2017). Court et al. (2017) demonstrated that UGT2B15*2 was associated with increased plasma concentrations of NAPQIprotein adducts, and that the plasma concentrations of the protein adducts negatively correlated with acetaminophen glucuronidation. Thus, carriers of rs1902023 may be slower metabolizers of acetaminophen glucuronidation, resulting in increased availability of acetaminophen for oxidative metabolism to NAPQI and subsequent liver damage.

Although a major limitation of these studies is the population size, the results are compelling. The association of these polymorphisms with acetaminophen-induced hepatotoxicity, along with their ethnic variations, should be investigated further. To overcome the challenges of the candidate gene approach in human populations with ALF resulting from acetaminophen toxicity, additional studies have used alternative approaches, such as GWAS, to identify SNPs that may serve as biomarkers for acetaminophen susceptibility.

\section{Genome-Wide Approaches to Identify SNPs Associated with Acetaminophen-Induced Hepatotoxicity}

To test the hypothesis that genetic polymorphisms downstream of NAPQI formation contribute to hepatotoxicity, Moyer et al. (2011) used a human variation panel of 176 lymphoblastoid cell lines established from healthy donors. The growth inhibitory effect of NAPQI $\left(\mathrm{IC}_{50}\right)$ was determined for

TABLE 1

Top human SNPs associated with acetaminophen-induced hepatotoxicity [Court et al. (2014), $n=78$ intentional, 79 unintentional, 103 control]

\begin{tabular}{|c|c|c|c|c|c|c|c|}
\hline SNP & Gene & Name & Alleles $^{a}$ & MAF & Category & Odds Ratio $^{b}$ & $P$ Value \\
\hline rs8330 & $U G T 1 A$ & UDP glucuronosyltransferase family 1 member A complex locus & $\mathrm{C} / \mathrm{G}$ & 0.26 & $3^{\prime} \mathrm{UTR}^{c}$ & $0.53(0.3-0.94)$ & 0.027 \\
\hline rs776746 & CYP3A5 & Cytochrome P450 family 3 subfamily A member 5 & G/A & 0.38 & Intron & $2.3(1.1-4.9)$ & 0.034 \\
\hline rs1467558 & $C D 44$ & CD44 molecule & $\mathrm{C} / \mathrm{T}$ & 0.06 & Missense & $4.0(1.0-17.2)$ & 0.045 \\
\hline
\end{tabular}

${ }^{a}$ Major allele/minor allele.

${ }^{b}$ OR $(95 \%$ confidence interval)

${ }^{c}$ Untranslated region. 
each cell line following 24 hours of treatment with seven doses $(0-100 \mu \mathrm{M})$ of NAPQI. Large variations in NAPQI IC 50 , ranging from 1 to $25 \mu \mathrm{M}(6.5 \pm 4.5 \mu \mathrm{M}$; mean \pm S.D. $)$, were detected between the 176 cell lines, suggesting a genetic component in NAPQI metabolism. To identify SNPs associated with NAPQI-induced hepatotoxicity, GWAS was performed using Illumina (San Diego, CA) Infinium HumanHap $550 \mathrm{~K}$ and $510 \mathrm{~S}$ bead chips and Affymetrix (Santa Clara, CA) 6.0 GeneChips.

Initially, Moyer et al. (2011) examined the association of $716 \mathrm{SNPs}$, located in 31 glutathione pathway genes, with NAPQI IC 50 . Only 45 SNPs had significant $P$ values $(<0.05)$, 24 of which were located in the multidrug resistance ATPbinding cassette, sub-family $\mathrm{C}$ (CFTR/MRP), member 3 (ABCC3), and member $4(A B C C 4)$ genes. Expression of $A b c c 3$ and $A b c c 4$ in mice upon acetaminophen-induced hepatotoxicity has been shown to be dependent upon the transcription factor, Nrf2 (Aleksunes et al., 2008). Nrf2 has been shown to play a protective role in acetaminophen-induced hepatotoxicity as $\mathrm{Nrf2}^{-1-}$ knockout mice were more susceptible to acetaminophen-induced liver damage compared with their wild-type $\mathrm{Nrf2}+/+$ controls (Enomoto et al., 2001). The remaining significant SNPs were located in or near glutamate cysteine ligase (GCLC), glutathione peroxidase ( $G P X 2, G P X 3, G P X 4$, and $G P X 7)$, glutathione synthetase (GSS), and glutathione transferase (GSTA2, GSTA3, and GSTP1). Two SNPs, E4p254 (GSTM1, $P=0.13$ ) and $16 \mathrm{~m} 18$ (GSTP1, $P=0.04)$, are not annotated in dbSNP database and, therefore, are not discussed further in this review.

Moyer et al. (2011) extended their study to a genome-wide SNP analysis in which 1,008,202 SNPs were screened for

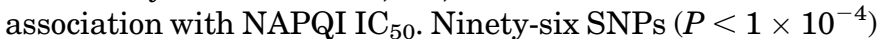
were associated with NAPQI $\mathrm{IC}_{50}$. Interestingly, 15 of the top20 significant SNPs mapped to intergenic regions. Ten of these 15 intergenic SNPs were clustered in a region of chromosome 3, between the C3orf38 and EPHA3 genes. Functional analysis of rs2880961, which lies $317 \mathrm{~kb}$ downstream of C3orf38, demonstrated binding of transcription factors, including NF- $\kappa$ B, HSF1, and HSF2 (Moyer et al., 2011). However, significant differences in NF- $\kappa \mathrm{B}, \mathrm{HSF}$, and HSF2TF binding were not detected by chromatin immunoprecipitation assays between wild-type and variant SNPs (Moyer et al., 2011). However, this does not preclude differential binding of other transcription factors. Thus, further analyses of these potential regulatory islands and their roles in NAPQI hepatotoxicity are warranted. The top-10 intragenic SNPs are located in the introns of genes (Table 2). These genes are involved in gene regulation (LMX1A), signal transduction (ETKN2, KCNJ3, $M C T P 1)$, immune response (IL23R, UBASH3A), extracellular matrix (SPAG16, LAMA4), and the detoxification of aldehydes generated by lipid peroxidation (ALDH1A3). The remaining gene, $R F P L 4 B$, which is poorly characterized, encodes a zincfinger protein. To identify potential cis effects of SNPs on gene expression, Moyer et al. (2011) measured mRNA expression using Affymetrix U133 Plus 2.0 GeneChips. Interestingly, 19 probe sets, representing 17 genes, were associated signif-

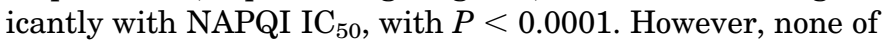
these 17 genes overlapped with genes containing SNPs, suggesting that the SNPs may have a trans effect on the expression of these genes (Moyer et al., 2011).

Two studies by Harrill et al. (2009a,b) identified potential susceptibility targets using a panel of 36 inbred mouse strains to model genetic diversity. Fasting mice were treated with $300 \mathrm{mg} / \mathrm{kg}$ acetaminophen by intragastric dosing. Food was reintroduced after 3 hours of acetaminophen dosing. After 24 hours, the mice were euthanized for analysis. The extent of liver injury was quantified by serum ALT levels. Haplotypeassociated mapping and targeted sequencing revealed that polymorphisms in $L y 86, C d 44, C d 59 a$, and Capn8 correlated with increased ALT levels. To determine if the orthologous human genes were also associated with acetaminopheninduced liver injury, genomic DNA from two independent cohorts, University of North Carolina (Harrill et al., 2009b) and Purdue Pharma (Watkins et al., 2006), was sequenced. Although Harrill et al. (2009b) did not detect SNP associations within LY86 and CD59, rs3749166 in CAPN10 (the human ortholog of mouse Capn8) $(P=0.045)$ and rs1467558 in CD44 $(P=0.002)$ were associated with elevated ALT levels in both cohorts. To validate these findings further, liver damage was measured in C57BL/6J Cd44 knockout mice administered acetaminophen. Cd44 knockout mice presented with greater liver injury $(61 \% \pm 7 \%$, mean liver necrosis \pm S.E. $)$ compared with wild-type controls $(40 \% \pm 4 \%)$ following a 24-hour dose of acetaminophen $(300 \mathrm{mg} / \mathrm{kg})$. These results indicate a role for CD44 in modulation of susceptibility to acetaminophen hepatotoxicity, as supported by Court et al. (2014). Further investigations of CD44 and CAPN10, as well as LY86 and $C D 59$, are needed to determine if they are indeed potential markers of enhanced risk of acetaminophen-induced hepatotoxicity. Harrill et al. (2009a) also performed mRNA microarray analyses on an Agilent (Santa Clara, CA) Mouse Toxicology Array (\#4121A) to identify gene-expression biomarkers for

TABLE 2

Intronic SNPs associated with NAPQI-induced hepatotoxicity [Moyer et al. (2011), $n=176$ ]

\begin{tabular}{lclcccc}
\hline \multicolumn{1}{c}{ SNP } & Gene & \multicolumn{1}{c}{ Name } & Alleles $^{a}$ & MAF & Category $P$ Value $^{b}$ \\
\hline rs1532815 & LMX1A & LIM homeobox transcription factor 1 alpha & A/T & 0.33 & Intron & $6.04 \mathrm{E}-7$ \\
rs3795578 & ETNK2 & Ethanolamine kinase 2 & C/T & 0.40 & Intron & $7.18 \mathrm{E}-6$ \\
rs3825924 & ALDH1A3 & Aldehyde dehydrogenase 1 family member A3 & C/T & 0.21 & Intron & $1.73 \mathrm{E}-5$ \\
rs1343151 & IL23R & Interleukin 23 receptor & G/A & 0.34 & Intron & $1.91 \mathrm{E}-5$ \\
rs17640676 & KCNJ3 & Potassium voltage-gated channel subfamily J member 3 & G/T & 0.23 & Intron & $2.09 \mathrm{E}-5$ \\
rs4869233 & MCTP1 & Multiple C2 and transmembrane domain containing 1 & T/C & 0.32 & Intron & $2.28 \mathrm{E}-5$ \\
rs16851554 & SPAG16 & Sperm associated antigen 16 & T/G & 0.15 & Intron & $2.46 \mathrm{E}-5$ \\
rs3208829 & LAMA4 & Laminin subunit alpha 4 & C/G & 0.16 & Intron & $2.54 \mathrm{E}-5$ \\
rs11153350 & RFPL4B & Ret finger protein like 4B & G/A & 0.15 & Intron & $2.54 \mathrm{E}-5$ \\
rs3746923 & UBASH3A & Ubiquitin associated and SH3 domain containing A & C/T & 0.43 & Intron & $2.56 \mathrm{E}-5$ \\
\hline
\end{tabular}

${ }^{a}$ Major allele/minor allele.

${ }^{b}$ The top-10 intronic SNPs based upon $P$ value are presented. 
acetaminophen hepatotoxicity in their panel of 36 inbred mouse strains. Gene-expression profiling identified 26 genes which were associated significantly with liver damage. Similar to the Moyer et al. (2011) study, these genes did not overlap with the hepatotoxicity SNPs identified in their mouse panel. This observation further supports the hypothesis that, in addition to affecting protein-coding regions, SNPs may disrupt noncoding regulatory regions. An alternative explanation is that the 26 genes function either upstream or downstream of the SNP-modified genes.

\section{Discussion}

As a leading cause of ALF, DILI both increases the cost of medical care and limits access to drugs which would normally be beneficial (Lee, 2003). In this review, we explored the SNPs associated with the intrinsic DILI associated with acetaminophen by highlighting the difficulties of genetic studies in cohorts with limited case and control populations while presenting a potentially useful perspective to elucidate additional insight into genetic variations that can be applied to all DILI GWAS studies.

Acetaminophen overdose is a major cause of hepatotoxicity in many developed countries and has been linked to the formation of reactive NAPQI-protein adducts resulting in increased oxidative damage, an enhanced immune response, and mitochondrial dysfunction, leading to apoptosis and/or necrosis. Currently, the primary therapy for acetaminophen overdose is the administration of $\mathrm{N}$-acetylcysteine, a glutathione precursor; however, the effective therapeutic window is limited once liver injury has occurred. Liver transplantation is the only effective therapy for patients who do not recover from primary therapy and management. Therefore, it is necessary to identify genetic markers that identify individuals who are at risk for acetaminophen-induced hepatotoxicity. Unfortunately, as demonstrated in this review, there remains very little human data investigating acetaminophen-induced hepatotoxicity. The majority of data have been generated using either in vitro or animal models. However, the studies reviewed in this article provide a strong starting point for the validation of these findings and the further investigation of potentially promising acetaminophen-susceptible biomarkers. Ultimately, these 147 SNPs will have to be examined experimentally to determine if they are intricately involved in acetaminophen metabolism or simply false positives due to experimental limitations. The identification of SNPs associated with acetaminophen-induced hepatotoxicity will provide novel insights into the mechanisms of acetaminophen metabolism and the potential for therapeutic interventions. Additional GWAS studies, including whole-genome sequencing and SNP-array assays, on larger cohorts of acetaminopheninduced ALI or ALF and the inclusion of large control populations are critical for the identification of additional biomarkers. Furthermore, the complex, and perhaps redundant, biochemical metabolism of acetaminophen in the liver suggests that it might be necessary to perform haplotype and diplotype multiloci analyses to identify a combination of SNP alleles associated with acetaminophen-induced hepatotoxicity rather than a single polymorphic allele.

In addition, the coupling of GWAS studies with transcriptome, metabolome, and expression quantitative trait loci analyses will facilitate mechanistic studies to elucidate the immunologic, mitochondrial, apoptotic, and necrotic pathways involved in acetaminophen-induced hepatotoxicity. These mechanistic and systematic studies will allow the identification of additional, and hopefully more effective, therapeutic targets not only to counter acetaminophen-induced hepatotoxicity but also to understand DILI on a broader scale.

\section{Authorship Contributions}

Participated in research design: Heruth, Li, L. Zhang, Ye.

Performed data analysis: Heruth, Shortt, N. Zhang.

Wrote or contributed to the writing of the manuscript: Heruth, Shortt, Ye.

\section{References}

Adjei AA, Gaedigk A, Simon SD, Weinshilboum RM, and Leeder JS (2008) Interindividual variability in acetaminophen sulfation by human fetal liver: implications for pharmacogenetic investigations of drug-induced birth defects. Birth Defects Res A Clin Mol Teratol 82:155-165.

Aleksunes LM, Slitt AL, Maher JM, Augustine LM, Goedken MJ, Chan JY, Cherrington NJ, Klaassen CD, and Manautou JE (2008) Induction of Mrp3 and Mrp4 transporters during acetaminophen hepatotoxicity is dependent on Nrf2. Toxicol Appl Pharmacol 226:74-83.

Birdwell KA, Decker B, Barbarino JM, Peterson JF, Stein CM, Sadee W, Wang D, Vinks AA, He Y, Swen JJ, et al. (2015) Clinical pharmacogenetics implementation consortium (CPIC) guidelines for CYP3A5 genotype and tacrolimus dosing. Clin Pharmacol Ther 98:19-24.

Bourdi M, Eiras DP, Holt MP, Webster MR, Reilly TP, Welch KD, and Pohl LR (2007) Role of IL-6 in an IL-10 and IL-4 double knockout mouse model uniquely susceptible to acetaminophen-induced liver injury. Chem Res Toxicol 20:208-216.

Chambers JC, Zhang W, Sehmi J, Li X, Wass MN, Van der Harst P, Holm H, Sanna S, Kavousi M, Baumeister SE, et al.; Alcohol Genome-wide Association (AlcGen) Consortium; Diabetes Genetics Replication and Meta-analyses (DIAGRAM+) Study; Genetic Investigation of Anthropometric Traits (GIANT) Consortium; Global Lipids Genetics Consortium; Genetics of Liver Disease (GOLD) Consortium; International Consortium for Blood Pressure (ICBP-GWAS); Meta-analyses of Glucose and Insulin-Related Traits Consortium (MAGIC) (2011) Genome-wide association study identifies loci influencing concentrations of liver enzymes in plasma. Nat Genet 43:1131-1138.

Chen R, Wang J, Zhang Y, Tang S, and Zhan S (2015) Key factors of susceptibility to anti-tuberculosis drug-induced hepatotoxicity. Arch Toxicol 89:883-897.

Chen W, Koenigs LL, Thompson SJ, Peter RM, Rettie AE, Trager WF, and Nelson SD (1998) Oxidation of acetaminophen to its toxic quinone imine and nontoxic catechol metabolites by baculovirus-expressed and purified human cytochromes P450 2E1 and 2A6. Chem Res Toxicol 11:295-301.

Cohen SD, Pumford NR, Khairallah EA, Boekelheide K, Pohl LR, Amouzadeh HR, and Hinson JA (1997) Selective protein covalent binding and target organ toxicity. Toxicol Appl Pharmacol 143:1-12.

Corcoran GB, Mitchell JR, Vaishnav YN, and Horning EC (1980) Evidence that acetaminophen and N-hydroxyacetaminophen form a common arylating intermediate, N-acetyl-p-benzoquinoneimine. Mol Pharmacol 18:536-542.

Corcoran GB, Racz WJ, Smith CV, and Mitchell JR (1985) Effects of N-acetylcysteine on acetaminophen covalent binding and hepatic necrosis in mice. J Pharmacol Exp Ther 232:864-872.

Court MH, Freytsis M, Wang X, Peter I, Guillemette C, Hazarika S, Duan SX, Greenblatt DJ, and Lee WM; Acute Liver Failure Study Group (2013) The UDPglucuronosyltransferase (UGT) $1 \mathrm{~A}$ polymorphism c.2042C $>\mathrm{G}(\mathrm{rs} 8330)$ is associated with increased human liver acetaminophen glucuronidation, increased UGT1A exon $5 \mathrm{a} / 5 \mathrm{~b}$ splice variant mRNA ratio, and decreased risk of unintentional acetaminophen-induced acute liver failure. J Pharmacol Exp Ther 345:297-307.

Court MH, Peter I, Hazarika S, Vasiadi M, Greenblatt DJ, and Lee WM; Acute Liver Failure Study Group (2014) Candidate gene polymorphisms in patients with acetaminophen-induced acute liver failure. Drug Metab Dispos 42:28-32.

Court MH, Zhu Z, Masse G, Duan SX, James LP, Harmatz JS, and Greenblatt DJ (2017) Race, gender, and genetic polymorphism contribute to variability in acetaminophen pharmacokinetics, metabolism, and protein-adduct concentrations in healthy African-American and European-American volunteers. J Pharmacol Exp Ther 362:431-440.

Critchley JA, Critchley LA, Anderson PJ, and Tomlinson B (2005) Differences in the single-oral-dose pharmacokinetics and urinary excretion of paracetamol and its conjugates between Hong Kong Chinese and Caucasian subjects. J Clin Pharm Ther 30:179-184.

Critchley JA, Nimmo GR, Gregson CA, Woolhouse NM, and Prescott LF (1986) Intersubject and ethnic differences in paracetamol metabolism. Br J Clin Pharmacol 22: 649-657.

Dahlin DC, Miwa GT, Lu AY, and Nelson SD (1984) N-acetyl-p-benzoquinone imine: a cytochrome P-450-mediated oxidation product of acetaminophen. Proc Natl Acad Sci USA 81:1327-1331.

Daly AK and Day CP (2012) Genetic association studies in drug-induced liver injury. Drug Metab Rev 44:116-126.

Daly AK, Donaldson PT, Bhatnagar P, Shen Y, Pe'er I, Floratos A, Daly MJ, Goldstein DB, John S, Nelson MR, et al.; DILIGEN Study; International SAE Consortium (2009) HLA-B*5701 genotype is a major determinant of drug-induced liver injury due to flucloxacillin. Nat Genet 41:816-819.

Davern TJ, II, James LP, Hinson JA, Polson J, Larson AM, Fontana RJ, Lalani E, Munoz S, Shakil AO, and Lee WM Acute Liver Failure Study Group (2006) 
Measurement of serum acetaminophen-protein adducts in patients with acute liver failure. Gastroenterology 130:687-694.

Dong H, Haining RL, Thummel KE, Rettie AE, and Nelson SD (2000) Involvement of human cytochrome P450 2D6 in the bioactivation of acetaminophen. Drug Metab Dispos 28:1397-1400.

Enomoto A, Itoh K, Nagayoshi E, Haruta J, Kimura T, O'Connor T, Harada T, and Yamamoto M (2001) High sensitivity of Nrf2 knockout mice to acetaminophen hepatotoxicity associated with decreased expression of ARE-regulated drug metabolizing enzymes and antioxidant genes. Toxicol Sci 59:169-177.

Fannin RD, Gerrish K, Sieber SO, Bushel PR, Watkins PB, and Paules RS (2016) Blood transcript immune signatures distinguish a subset of people with elevated serum ALT from others given acetaminophen. Clin Pharmacol Ther 99:432-441.

Fontana RJ (2014) Pathogenesis of idiosyncratic drug-induced liver injury and clinical perspectives. Gastroenterology 146:914-928.

Harrill AH, Ross PK, Gatti DM, Threadgill DW, and Rusyn I (2009a) Populationbased discovery of toxicogenomics biomarkers for hepatotoxicity using a laboratory strain diversity panel. Toxicol Sci 110:235-243.

Harrill AH, Watkins PB, Su S, Ross PK, Harbourt DE, Stylianou IM, Boorman GA, Russo MW, Sackler RS, Harris SC, et al. (2009b) Mouse population-guided resequencing reveals that variants in CD44 contribute to acetaminophen-induced liver injury in humans. Genome Res 19:1507-1515.

Hayashi S, Watanabe J, and Kawajiri K (1991) Genetic polymorphisms in the 5 'flanking region change transcriptional regulation of the human cytochrome P450IIE1 gene. J Biochem 110:559-565.

Hinson JA, Roberts DW, and James LP (2010) Mechanisms of acetaminopheninduced liver necrosis. Handb Exp Pharmacol 196:369-405.

Jiang J, Briedé JJ, Jennen DG, Van Summeren A, Saritas-Brauers K, Schaart G, Kleinjans JC, and de Kok TM (2015) Increased mitochondrial ROS formation by acetaminophen in human hepatic cells is associated with gene expression changes suggesting disruption of the mitochondrial electron transport chain. Toxicol Lett 234:139-150

Jollow DJ, Mitchell JR, Potter WZ, Davis DC, Gillette JR, and Brodie BB (1973) Acetaminophen-induced hepatic necrosis. II. Role of covalent binding in vivo. $J$ Pharmacol Exp Ther 187:195-202.

Kimura K, Hayashi S, and Nagaki M (2010) Roles of CD44 in chemical-induced liver injury. Curr Opin Drug Discov Devel 13:96-103.

Krasniak AE, Knipp GT, Svensson CK, and Liu W (2014) Pharmacogenomics of acetaminophen in pediatric populations: a moving target. Front Genet 5:314.

Kuehl P, Zhang J, Lin Y, Lamba J, Assem M, Schuetz J, Watkins PB, Daly A, Wrighton SA, Hall SD, et al. (2001) Sequence diversity in CYP3A promoters and characterization of the genetic basis of polymorphic CYP3A5 expression. Nat Genet 27:383-391.

Kurtovic J and Riordan SM (2003) Paracetamol-induced hepatotoxicity at recommended dosage. J Intern Med 253:240-243.

Laine JE, Auriola S, Pasanen M, and Juvonen RO (2009) Acetaminophen bioactivation by human cytochrome $\mathrm{P} 450$ enzymes and animal microsomes. Xenobiotica 39:11-21.

Lee SS, Buters JT, Pineau T, Fernandez-Salguero P, and Gonzalez FJ (1996) Role of CYP2E1 in the hepatotoxicity of acetaminophen. J Biol Chem 271:12063-12067. Lee WM (2003) Drug-induced hepatotoxicity. N Engl J Med 349:474-485.

Lee WM (2013) Drug-induced acute liver failure. Clin Liver Dis 17:575-586, viii.

Leeming MG, Gamon LF, Wille U, Donald WA, and O'Hair RAJ (2015) What are the potential sites of protein arylation by N-Acetyl-p-benzoquinone imine (NAPQI)? Chem Res Toxicol 28:2224-2233.

Lucena MI, Molokhia M, Shen Y, Urban TJ, Aithal GP, Andrade RJ, Day CP, Ruiz-Cabello F, Donaldson PT, Stephens C, et al.; Spanish DILI Registry; EUDRAGENE; DILIN; DILIGEN; International SAEC (2011) Susceptibility to amoxicillin-clavulanate-induced liver injury is influenced by multiple HLA class I and II alleles. Gastroenterology 141:338-347.

Marzilawati AR, Ngau YY, and Mahadeva S (2012) Low rates of hepatotoxicity among Asian patients with paracetamol overdose: a review of 1024 cases. BMC Pharmacol Toxicol 13:8.

McGill MR, Lebofsky M, Norris HR, Slawson MH, Bajt ML, Xie Y, Williams CD, Wilkins DG, Rollins DE, and Jaeschke H (2013) Plasma and liver acetaminophenprotein adduct levels in mice after acetaminophen treatment: dose-response, mechanisms, and clinical implications. Toxicol Appl Pharmacol 269:240-249.

McGill MR, Sharpe MR, Williams CD, Taha M, Curry SC, and Jaeschke H (2012) The mechanism underlying acetaminophen-induced hepatotoxicity in humans and mice involves mitochondrial damage and nuclear DNA fragmentation. J Clin Invest 122 $1574-1583$.

Mehboob H, Tahir IM, Iqbal T, Saleem S, Perveen S, and Farooqi A (2017) Effect of UDP-glucuronosyltransferase (UGT) 1A polymorphism (rs8330 and rs10929303) on glucuronidation status of acetaminophen. Dose Response 15:1559325817723731.

Mosedale M and Watkins PB (2017) Drug-induced liver injury: advances in mechanistic understanding that will inform risk management. Clin Pharmacol Ther 101:469-480

Moyer AM, Fridley BL, Jenkins GD, Batzler AJ, Pelleymounter LL, Kalari KR, Ji Y, Chai Y, Nordgren KK, and Weinshilboum RM (2011) Acetaminophen-NAPQI hepatotoxicity: a cell line model system genome-wide association study. Toxicol Sci 120:33-41.

Navarro SL, Chen Y, Li L, Li SS, Chang JL, Schwarz Y, King IB, Potter JD, Bigler J, and Lampe JW (2011) UGT1A6 and UGT2B15 polymorphisms and acetaminophen conjugation in response to a randomized, controlled diet of select fruits and vegetables. Drug Metab Dispos 39:1650-1657.
Ni HM, McGill MR, Chao X, Du K, Williams JA, Xie Y, Jaeschke H, and Ding WX (2016) Removal of acetaminophen protein adducts by autophagy protects against acetaminophen-induced liver injury in mice. J Hepatol 65:354-362.

Nicoletti P, Aithal GP, Bjornsson ES, Andrade RJ, Sawle A, Arrese M, Barnhart HX, Bondon-Guitton E, Hayashi PH, Bessone F, et al.; International Drug-Induced Liver Injury Consortium, Drug-Induced Liver Injury Network Investigators, and International Serious Adverse Events Consortium (2017) Association of liver injury from specific drugs, or groups of drugs, with polymorphisms in HLA and other genes in a genome-wide association study. Gastroenterology 152:1078-1089.

Nicoletti P, Werk AN, Sawle A, Shen Y, Urban TJ, Coulthard SA, Bjornsson ES, Cascorbi I, Floratos A, Stammschulte T, et al.; International Drug-induced Liver Injury Consortium (2016) HLA-DRB1*16: 01-DQB1*05: 02 is a novel genetic risk factor for flupirtine-induced liver injury. Pharmacogenet Genomics 26:218-224.

Nourjah P, Ahmad SR, Karwoski C, and Willy M (2006) Estimates of acetaminophen (paracetomal)-associated overdoses in the United States. Pharmacoepidemiol Drug Saf 15:398-405.

Patel M, Tang BK, and Kalow W (1992) Variability of acetaminophen metabolism in Caucasians and Orientals. Pharmacogenetics 2:38-45.

Petros Z, Lee MM, Takahashi A, Zhang Y, Yimer G, Habtewold A, Amogne W, Aderaye G, Schuppe-Koistinen I, Mushiroda T, et al. (2016) Genome-wide association and replication study of anti-tuberculosis drugs-induced liver toxicity. $B M C$ Genomics 17:755

Petros Z, Makonnen E, and Aklillu E (2017) Genome-wide association studies for idiosyncratic drug-induced hepatotoxicity: looking back-looking forward to nextgeneration innovation. OMICS 21:123-131.

Raheja KL, Linscheer WG, and Cho C (1983) Hepatotoxicity and metabolism of acetaminophen in male and female rats. J Toxicol Environ Health 12:143-158.

Ramachandran A and Jaeschke H (2017) Mechanisms of acetaminophen hepatotoxicity and their translation to the human pathophysiology. J Clin Transl Res $\mathbf{3}$ (Suppl 1):157-169.

Raucy JL, Lasker JM, Lieber CS, and Black M (1989) Acetaminophen activation by human liver cytochromes P450IIE1 and P450IA2. Arch Biochem Biophys 271 270-283.

Russmann S, Jetter A, and Kullak-Ublick GA (2010) Pharmacogenetics of druginduced liver injury. Hepatology 52:748-761.

Russmann S, Kullak-Ublick GA, and Grattagliano I (2009) Current concepts of mechanisms in drug-induced hepatotoxicity. Curr Med Chem 16:3041-3053.

Russo MW, Galanko JA, Shrestha R, Fried MW, and Watkins P (2004) Liver transplantation for acute liver failure from drug induced liver injury in the United States. Liver Transpl 10:1018-1023.

Satirapoj B, Lohachit P, and Ruamvang T (2007) Therapeutic dose of acetaminophen with fatal hepatic necrosis and acute renal failure. $J$ Med Assoc Thai 90: 1244-1247.

Tanaka K, Terao C, Ohmura K, Takahashi M, Nakashima R, Imura Y, Yoshifuji H, Yukawa N, Usui T, Fujii T, et al. (2014) Significant association between CYP3A5 polymorphism and blood concentration of tacrolimus in patients with connective tissue diseases. J Hum Genet 59:107-109.

Thummel KE, Lee CA, Kunze KL, Nelson SD, and Slattery JT (1993) Oxidation of acetaminophen to N-acetyl-p-aminobenzoquinone imine by human CYP3A4. Biochem Pharmacol 45:1563-1569.

Tirmenstein MA and Nelson SD (1989) Subcellular binding and effects on calcium homeostasis produced by acetaminophen and a nonhepatotoxic regioisomer, $3^{\prime}$ hydroxyacetanilide, in mouse liver. J Biol Chem 264:9814-9819.

Tsutsumi M, Wang JS, Takase S, and Takada A (1994) Hepatic messenger RNA contents of cytochrome P4502E1 in patients with different P4502E1 genotypes. Alcohol Alcohol Suppl 29:29-32.

Ueshima Y, Tsutsumi M, Takase S, Matsuda Y, and Kawahara H (1996) Acetaminophen metabolism in patients with different cytochrome P-4502E1 genotypes. Alcohol Clin Exp Res 20 (1 Suppl):25A-28A

Urban TJ, Shen Y, Stolz A, Chalasani N, Fontana RJ, Rochon J, Ge D, Shianna KV, Daly AK, Lucena MI, et al.; Drug-Induced Liver Injury Network; DILIGEN; EUDRAGENE; Spanish DILI Registry; International Serious Adverse Events Consortium (2012) Limited contribution of common genetic variants to risk for liver injury due to a variety of drugs. Pharmacogenet Genomics 22:784-795.

Vermeulen NP, Bessems JG, and Van de Straat R (1992) Molecular aspects of paracetamol-induced hepatotoxicity and its mechanism-based prevention. Drug Metab Rev 24:367-407.

Wang X, Wu Q, Liu A, Anadón A, Rodríguez JL, Martínez-Larrañaga MR, Yuan Z, and Martínez MA (2017) Paracetamol: overdose-induced oxidative stress toxicity, metabolism, and protective effects of various compounds in vivo and in vitro. Drug Metab Rev 49:395-437.

Wang X, Zhang L, and Jiang Z (2015) T-helper cell-mediated factors in drug-induced liver injury. J Appl Toxicol 35:695-700.

Watkins PB, Kaplowitz N, Slattery JT, Colonese CR, Colucci SV, Stewart PW, and Harris SC (2006) Aminotransferase elevations in healthy adults receiving 4 grams of acetaminophen daily: a randomized controlled trial. JAMA 296:87-93.

Zhao L and Pickering G (2011) Paracetamol metabolism and related genetic differences. Drug Metab Rev 43:41-52.

Address correspondence to: Dr. Daniel P. Heruth, Children's Mercy, 2601 Gillham Road, Kansas City, MO 64068. E-mail: dpheruth@cmh.edu 